\title{
Study on Optimization of Extraction Method of Total Alkaloids from Zizyphi Spinosi Semen \\ HU Yan-zhou ${ }^{1, a}$, DING Ke $e^{1, b *}$, CHEN Xiang-ning ${ }^{1, c}$, HAN Tao $^{1, d}$ \\ ${ }^{1}$ Department of Food Science and Engineering, Beijing Laboratory of Food Quality and Safety, Beijing University of Agriculture, Beijing 102206, China

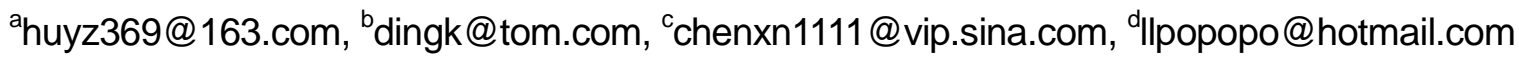

Keywords: Zizyphi spinosi semen, alkaloids, extract, reflux

Abstract. To obtain the best appropriate method and optimum extraction conditions of total alkaloids from Zizyphi spinosi semen (ZSS), the conditions of reflux extraction were optimized by single factor experiment and orthogonal design respectively. the experiment results were as follows: $20 \%$ acetic acid resolved in ethanol as extracting solvent ( $\mathrm{EtOH}: \mathrm{HAc}=80: 20(\mathrm{v} / \mathrm{v})$ ), ratio of liquid to solid $=20: 1(\mathrm{ml} / \mathrm{g}), 4.0 \mathrm{~h}, 70{ }^{\circ} \mathrm{C}$, and these conditions were optimum conditions after validation of experiment. The total alkaloids of ZSS extracted by this method could provide a powerful guarantee for studying ingredients and activities of alkaloids in ZSS.

\section{Introduction}

Zizyphi spinosi semen (ZSS) both belongs to food and medicine as one of a Chinese medicine, is the seed of Zizyphus jujuba Mill. Var. spinosa (Bunge) Hu ex H. F. Chou (Rhamnaceae). As a Chinese medicine, ZSS has a long history, it has been mainly used for curing the insomnia, palpitation and dreaminess, Tixu and hyperhidrosis, impairment of body fluids and thirst, and so ${ }^{\text {on }}{ }^{[1]}$. ZSS is produced at the mountain area in the north of China, such as HeBei, ShanXi, ShanDong, ShanXi, Liaoning, HeNan, Inner Mongolia ${ }^{[2]}$.

So far, currnet reports mainly foucs on the function of alkaloids about sedative and hypnotic effect of $Z S S^{[3-5]}$. In addition, Wei Qiao et al. study on the fuction of Anticonvulsive effect ${ }^{[6]}$ and antidepressant effect of $Z S S^{[7]}$. The results of his study show that compared the group of $20 \mathrm{mg} / \mathrm{kg}$ cyclopeptide alkaloids, the group of $50 、 100 \mathrm{mg} / \mathrm{kg}$ total alkaloids of ZSS could lead to the death time and seizure time of mice were significantly prolonged. As the conclusion, it means alkaloids of $Z S S$ act out the statistical significance that contain anti convulsion effect ${ }^{[6]}$, the total alkaloids of ZSS could shorten the immobileity time of mouse tail related to the different kind agent with different dosage, and confront mice body temperature deline due to reserpine effectively, blank experiments in each group between the spontaneous activity of the mice without significant difference also shows that alkaloids of ZSS, in a certain degree, it has the effect of anti depression ${ }^{[7]}$.

The mainly methods to extract the total alkaloids are solvent method, infiltration percolation film evaporation continuous extraction, supercritical fluid extraction, ultrasonic assisted extraction, membrane extraction, microwave assisted extraction and so on ${ }^{[8]}$. The most common one is solvent method, and the efficiency of this method is ralted to the solvent dosage, raw material grinding degree, operating conditions (including temperature, stirring, etc.) closely. Depend on the different character of alkaloids, the solvent extraction could be divided into four types: pure water, acid water-organic solvent $(0.5 \sim 1.0 \%$ acetic acid, hydrochloric acid as solvent), alcohol or alkaline organic solvent. Total alkaloids from securinine, anabasine ${ }^{[9]}$ or nuciferine ${ }^{[10]}$ were extracted by using water as solvent. Alkaloids in Bat Ge crude existing as unstable salt or dissociative alkali were obtained by acid water - organic solvent extraction ${ }^{[11]}$. Total alkaloids from Wu Zhuyu were extracted by using $70 \%$ methanol reflux extraction $24 \mathrm{~h}^{[12]}$. Alkalized chloroform is the best for 
alkaloids from Yan Husuo ${ }^{[13]}$.

Current research shows that, ZSS contains two main kinds of alkaloids, namely aporphine alkaloids and cyclopeptide alkaloids ${ }^{[14-20]}$. Besides, one of cyclopeptide alkaloids-- sanjoinine A has the function as physiological activity ${ }^{[16]}$. In recent years, with the in-depth study on active components of semen ziziphi spinosae alkaloid, its function have been achieved more and more attention, so we need to find an effective method of ZSS alkaloid extraction that is the basis for the subsequent researches on it. This research foucs on the extraction process of ZSS alkaloid in order to get an simple and effciency method.

\section{Materials and Methods}

Experimental materials and apparatus

ZSS (purchased in Hebei Anguo herbal medicine market); bromocresol green (analytical pure, Beijing XinNuo JiuHeng Technology \& Trade Co., Ltd.). Anhydrous ethanol, petroleum ether, chloroform, potassium hydroxide, ammonia, sulfuric acid, hydrochloric acid, acetic acid, anhydrous sodium sulfate, adjacent benzene two formic acid hydrogen potassium (analytical pure, Beijing chemical factory).

Ultraviolet - visible spectrophotometry meter (TU-1810 type, Beijing PuXi General Instrument Co., Ltd.); Electronic balance (ALC-210.3 type, Beijing SaiDuoRuiSi instrument Co., Ltd.); Chinese herbal medicine pulverizer (FW135 type, Tianjin TaiSiTe instrument Co., Ltd.); Heat heating thermostat magnetic stirrer (DF-1013, Zhengzhou Greatwall Science Industry \& Trade Co., Ltd); Low speed centrifuge (GL-20B, Shanghai Anting Scientific Instrument Factory); Rotary evaporator (RE-2000, the Shanghai YaRongSheng biochemical instrument factory).

Experimental

The analysis method of ZSS alkaloids-- spectrophotography

(1) Experiment principle

Alkaloid substances dissolved in aqueous solution with a certain $\mathrm{pH}$ value combine with dissociative hydrogen ions to form salt $\left(\mathrm{BH}^{+}\right)$, and at the same time, add some acid dyes (such as bromine phenol blue, bromothymol blue, bromocresol green, etc.), then dyes can be dissociated as anions $\left(\mathrm{In}^{-}\right)$. The cation $\mathrm{BH}^{+}$and anion $\mathrm{In}^{-}$could be combined to form a colored ion pair $\left(\mathrm{In}^{-}, \mathrm{BH}^{+}\right)$ quantitatively, which can be extracted by organic solvent, and enter organic phase by aqueous phase.

$$
B+H^{+} \Leftrightarrow B H^{+} \quad \text { (1) } \quad H I n \Leftrightarrow H^{+}+I^{-}
$$

As (1) and (2) showed:

$p H \downarrow$ (acidity) $\rightarrow B H^{+} \uparrow, I^{-} \downarrow \rightarrow B H^{+} I n^{-} \downarrow$, HIn is extracted by organic solvent;

$p H \uparrow$ (alkalinity) $\rightarrow \operatorname{In}^{-} \uparrow, B H^{+} \downarrow \rightarrow B H^{+} I^{-} \downarrow$, B is extracted by organic solvent.

The staining range of bromocresol green is 3.6 5.2 (Yellow $\sim$ Blue), so the $\mathrm{pH} 4.5$ buffer and $\mathrm{pH}$ 4.5 bromocresol green reagent were selected to be dyed.

Because of no standards of ZSS alkaloids right, The total alkaloids had been extraced from $50 \mathrm{~g}$ defatted ZSS powder when using spectrophotometry in each improved experiment to make the results of the experiment could be compared. Then, calculate the mass of extractions from ZSS per gram. After that, those extractions from every 2 grams of ZSS raw materials was detected by the spectrophotometry to get total amount of alkaloid. At the end, if the light absorption value from aqueous phase of the sample is less and less and from chloroform phase of the sample is more and more that means the content of alkaloids in the extracts was much more. As the result the optimal extraction method can be determined.

(2) Preparation of reagent

(1) Bromocresol green solution

$0.1 \mathrm{~mol} / \mathrm{L}$ Potassium hydroxide solution: weigheing $56.000 \mathrm{~g}$ potassium hydroxide accurately, adding deionized water until $50 \mathrm{ml}$ 
$0.2 \mathrm{~mol} / \mathrm{L}$ Potassium acid phthalate buffer solution ( $\mathrm{pH} 4.5$ ): weigheing $40.846 \mathrm{~g}$ Potassium acid phthalate accurately, adding deionized water until $1000 \mathrm{ml}$, adding $0.1 \mathrm{~mol} / \mathrm{L}$ potassium hydroxide solution to $\mathrm{pH} 4.5$;

Bromocresol green solution: weigheing $15 \mathrm{mg}$ bromocresol green accurately, adding $\mathrm{pH} 4.5$ phthalate buffer solution until $500 \mathrm{ml}$.

(2) Preparation of sample solution

Taking an extractive from one extracting experiment as example: first weighing extract total quality, according to the total quality of extract and the use ratio of raw material quality ZSS calculated corresponding to every $2 \mathrm{~g}$ of ZSS extract quality. Firstly measuring the total quality of extractions, according to the ratio of total quality and raw material quality of ZSS, calculating the extraction quality from each $2 \mathrm{~g} Z S S$; weighting the extractions quality from $2 \mathrm{~g}$ raw material of ZSS, and dissolved in chloroform. During this process, adding a bit of ammonia to cacelerate the dissolution process. At the end, adding chloroform until $25 \mathrm{ml}$.

(3) Determination of total alkaloids

(1) Liquid extraction

Taking the same solution three times separately as $0.50 \mathrm{ml}, 1 \mathrm{ml}, 2 \mathrm{ml} 20 \mathrm{ml}$ to the centrifuge tube, and adding chloroform solution until $5.00 \mathrm{ml}$, then adding $5 \mathrm{ml}$ bromocresol green solution, shaking well and puting into $30{ }^{\circ} \mathrm{C}$ water bath for $5 \mathrm{~min}$, and $1000 \mathrm{rpm}$ speed centrifuge for $5 \mathrm{~min}$.

(2) Determination of total alkaloid in aqueous phase

The aqueous phase (upper phase) of each centrifugal tube was transferred into a plug scale test tube by a straw. Additionally, the potassium hydroxide buffer solution was used as the blank, and the absorbance was measured at $616 \mathrm{~nm}$ and recorded the value A.

(3) Determination of total alkaloids in chloroform solution

The chloroform phase (under phase) in centrifugal tube was put into another a plug scale test tube with $2 \mathrm{~g}$ of anhydrous sodium sulfate, shaking and then keeping staying for 1 hour. Moreover, using chloroform as blank, measuring the absorbance under $416 \mathrm{~nm}$ and recording value A.

The extraction method of total alkaloids of ZSS

(1) Process flow chart

Show as Figure 1

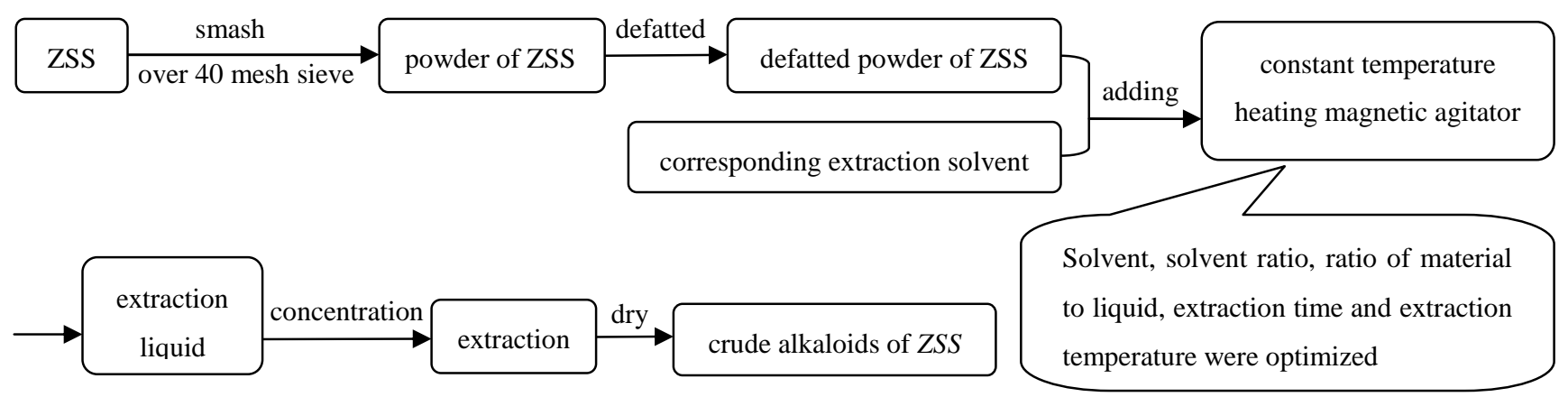

Figure 1 Processing flowsheet of the reflux exrtraction of alkaloid in ZSS

(2) The single factor optimal experiment of total alkaloids extraction conditions from ZSS

(1) Optimization of extraction solvent

Firstly, putting $50 \mathrm{~g}$ skim powder from ZSS to $1000 \mathrm{ml}$ three flasks, and adding the $1000 \mathrm{ml}$ different extraction agents to flasks (respectively: 5\% glacial acetic acid water solution, 5\% glacial acetic acid ethanol solution, 5\% ammonia solution) until the liquid to solid ratio was $20: 1$ (ml:g). Secondly, the three flasks were put in a constant temperature heating magnetic stirrer keeping the same speed at $60{ }^{\circ} \mathrm{C}$ for 6 hours. Thridly, extracting solution would be centrifugal under $4000 \mathrm{rpm}$ for $10 \mathrm{~min}$. After that, in order to compared the different effect of different extraction solvent, the centrifugal supernatant was concentrated by a rotary evaporator, and when the liquid volume was 
less transfer to the $100 \mathrm{ml}$ flask with a plug conical to evaporate until totally dry. Finally, move to the vacuum drying apparatus to dry for 2 or 3 days.

(2) Optimization of acid in extraction solvent

Similarity, the process is same as (1), this step focus on adding different acid (Respectively: glacial acetic acid, hydrochloric acid, sulfuric acid) to extraction solvent to get the better extraction effect. Besides, the extraction solvent was ethanol as well, and the other conditions were same as (1).

(3) Orthogonal test conditions for extracting total alkaloids of ZSS

The total alkaloids extraction of ZSS have been effected by 8 factors: extraction method, the granularity of raw materials, solvents, extraction times and solvent concentration, solid-liquid ratio, extraction temperature, extraction time and the eight factors. In this research, extraction method, the size of raw material, solvent type, extraction times, these four factors have been chose. Using granularity of raw material which go through 40-50 mesh and glacial acetic acid ethanol solution as extracting agent, the orthogonal optimization was carried out on four factors: solvent concentration, solid-liquid ratio, extraction temperature and extraction time by refluxing extraction. These four factors and level results as shown in Table 1. Additionally, According to the factors and the level of orthogonal table, $\mathrm{L}_{16}\left(4^{5}\right)$ was chose to be the orthogonal experiment scheme.

Table1 Factors and levels of the reflux exrtraction of alkaloid in ZSS

\begin{tabular}{ccccc}
\hline & $\begin{array}{c}\text { Temp. } \\
\left({ }^{\circ} \mathrm{C}\right)\end{array}$ & $\begin{array}{c}\text { Time } \\
(\mathrm{h})\end{array}$ & $\begin{array}{c}\text { Ratio } \\
(\mathrm{g}: \mathrm{ml})\end{array}$ & $\begin{array}{c}\text { Ethanol Conc. } \\
(\%)\end{array}$ \\
\hline 1 & 50 & 2 & $1: 5$ & 95 \\
2 & 60 & 4 & $1: 10$ & 90 \\
3 & 70 & 6 & $1: 15$ & 85 \\
4 & 80 & 8 & $1: 20$ & 80 \\
\hline
\end{tabular}

(4) Verification of optimal extraction conditions

According to the results of single factor experiment and orthogonal experiment, the optimal extraction conditions are verified by experiments to make sure this conditions if is the real best extraction way for this reaserch.

\section{Results and Discussion}

The results and discussion of optimization extraction conditions of single factor experimen

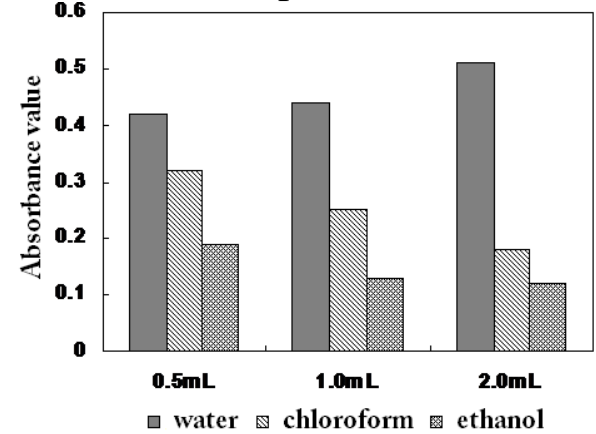

(a) Results of aqueous phase

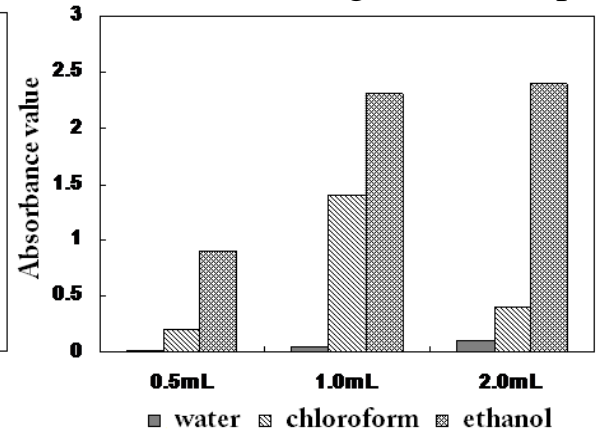

(b) Results of Chloroform phase



(c) Extraction rate

Figure 2 comparation of different extract solvent 
Optimization of extraction solvent

Figure 2 is the result of the optimization of the extraction solvent, from the graph (a) can be seen that the ethanol extract in the aqueous phase of the lowest absorbance value, the highest water extract, chloroform extract in the middle. Figure 2 is the result of the optimization of the extraction solvent. Moreover, from the graph (a) can be seen that the ethanol extract of the aqueous phase is lowest absorbance value, the highest is water extract, chloroform extract is in the middle. From the graph (b), ethanol extract in chloroform phase is the highest absorbance value, the lowest is water extract, chloroform extract is in the middle. previous principle of analysis method, the lower the absorbance of the aqueous phase, the higher the value of the content of alkaloids in the extract, which means the higher the content of alkaloids in the extract. Therefore, the content of alkaloids in ethanol extract was the highest, the next was chloroform, and the content of water extract was the lowest. On the other side, from the results of extraction rate (Figure 2: (c)) showed as, extraction rate from high to low in order is water >ethanol>chloroform. Although, the extract of water is the most, but the content of alkaloid is the lowest, and the impurities are more, and the extraction rate is lowest. Besides, solvents are toxic. Finally, considered abll above factors, ethanol have been chose as the extraction solvent.

Optimization of acid in solvent extraction

Figure 3 is the result of the optimization of the acid in the solvent. From the graph (a) can be seen that the extract of sulfuric acid in the aqueous phase is the lowest absorbance value, the highest is hydrochloric acid extract, acetic acid extract is in the middle. From the graph (b), acetic acid extractin chloroform phase is the highest absorbance value, the lowest is hydrochloric acid extract, sulfuric acid is in the middle. Therefore, it can be judged that the content of alkaloid in the extract of acetic acid is the highest, and the second is the lowest, and the content of alkaloid in the extract is the lowest. Therefore, the content of alkaloids in adding acetic acid extract was the highest, the next is adding sulfuric acid, and the content of adding hydrochloric acid extract was the lowest. On the other hand, it can be seen from Figure (c), the extraction rate from high to low in order is sulfuric acid >hydrochloric acid> acetic acid. Although, the extract of water is the lowest, but the content of alkaloid is the most, and the impurities are less, and effiency is high. While, the effiency of adding sulfuric acid is really high, but there are impurities as well. So, acetic acid have been chose as the solvent for extraction.

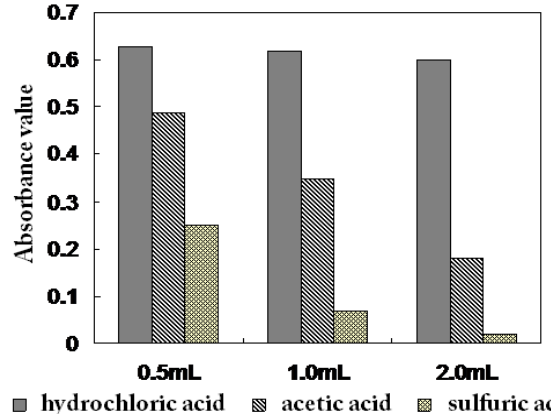

(a) Results of aqueous phase

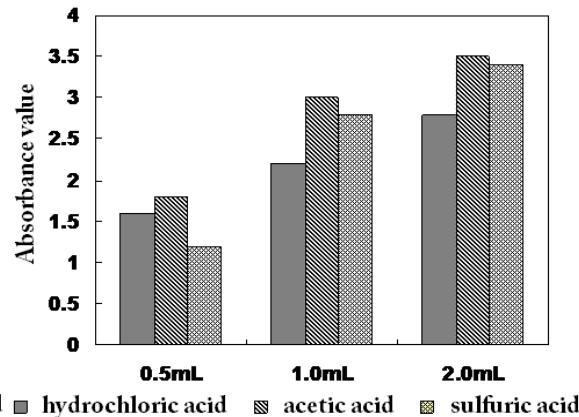

(b) Results of Chloroform phase

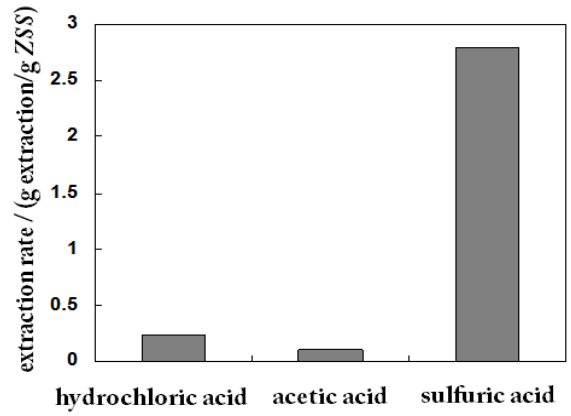

(c) Extraction rate

Figure 3 comparation of different acid in extract solution 
The results and discussion of optimization extraction conditions of orthogonal tests

Extraction rate

As table 2 showed, according to the value of range (R) we can see that the efficacy of ZSS alkaloids have been influenced by four factors from high to low in order are solid ratio>extraction temperature>extraction time>ethanol concentration. In summary, the combination of optimal factors are: $95 \%$ ethanol in solid:liquid equal 10:1 solution under $70{ }^{\circ} \mathrm{C}$ for $8 \mathrm{~h}$

Table $2 \mathrm{~L}_{16}\left(4^{5}\right)$ Project of orthogonal tests and the results of the reflux exrtraction of alkaloid

\begin{tabular}{|c|c|c|c|c|c|c|}
\hline NO. & $\begin{array}{l}\text { Temp. } \\
\left({ }^{\circ} \mathrm{C}\right)\end{array}$ & $\begin{array}{l}\text { Time } \\
\text { (h) }\end{array}$ & $\begin{array}{l}\text { Ratio } \\
\text { (g: } \mathrm{ml})\end{array}$ & $\begin{array}{c}\text { EtOH Conc. } \\
(\%)\end{array}$ & Blank & $\begin{array}{c}\text { Extraction rate } \\
\text { (mg Extractive/g ZSS) }\end{array}$ \\
\hline 1 & 1 & 1 & 1 & 1 & 1 & 44.7 \\
\hline 2 & 1 & 2 & 2 & 2 & 2 & 87.6 \\
\hline 3 & 1 & 3 & 3 & 3 & 3 & 91.1 \\
\hline 4 & 1 & 4 & 4 & 4 & 4 & 122.9 \\
\hline 5 & 2 & 1 & 2 & 3 & 4 & 98.8 \\
\hline 6 & 2 & 2 & 1 & 4 & 3 & 80.2 \\
\hline 7 & 2 & 3 & 4 & 1 & 2 & 115.0 \\
\hline 8 & 2 & 4 & 3 & 2 & 1 & 96.7 \\
\hline 9 & 3 & 1 & 3 & 4 & 2 & 130.8 \\
\hline 10 & 3 & 2 & 4 & 3 & 1 & 128.7 \\
\hline 11 & 3 & 3 & 1 & 2 & 4 & 57.5 \\
\hline 12 & 3 & 4 & 2 & 1 & 3 & 946.3 \\
\hline 13 & 4 & 1 & 4 & 2 & 3 & 143.6 \\
\hline 14 & 4 & 2 & 3 & 1 & 4 & 98.8 \\
\hline 15 & 4 & 3 & 2 & 4 & 1 & 123.7 \\
\hline 16 & 4 & 4 & 1 & 3 & 2 & 87.7 \\
\hline Mean Value & 86.575 & 104.475 & 67.525 & 301.200 & 98.450 & \\
\hline Mean Value & 97.675 & 98.825 & 314.100 & 96.350 & 105.275 & \\
\hline Mean Value & 315.825 & 96.825 & 104.350 & 101.575 & 315.300 & \\
\hline Mean Value & 113.450 & 313.400 & 127.550 & 114.400 & 94.500 & \\
\hline Range & 229.250 & 216.575 & 246.575 & 204.850 & 220.800 & \\
\hline $\begin{array}{l}\text { Optimal } \\
\text { Level }\end{array}$ & A3 & B4 & $\mathrm{C} 2$ & D1 & & \\
\hline
\end{tabular}

Result of Determination content of extract alkaloids in orthogonal experiment

From table 3 it could be seen that the results of the 3 different sampling volume phase. According to the value of range (R), the efficacy of ZSS alkaloids have been influenced by four factors from high to low in order are solid to liquid ratio > ethanol concentration > extraction time>extraction temperature. In summary, the combination of optimal factors are $80 \%$ ethanol in solid : liquid equal 20:1 solution under $80^{\circ} \mathrm{C}$ for $4 \mathrm{~h}$

Table $3 \mathrm{~L}_{16}\left(4^{5}\right)$ Project of orthogonal tests and the results of alkaloid determining in aqueous phase

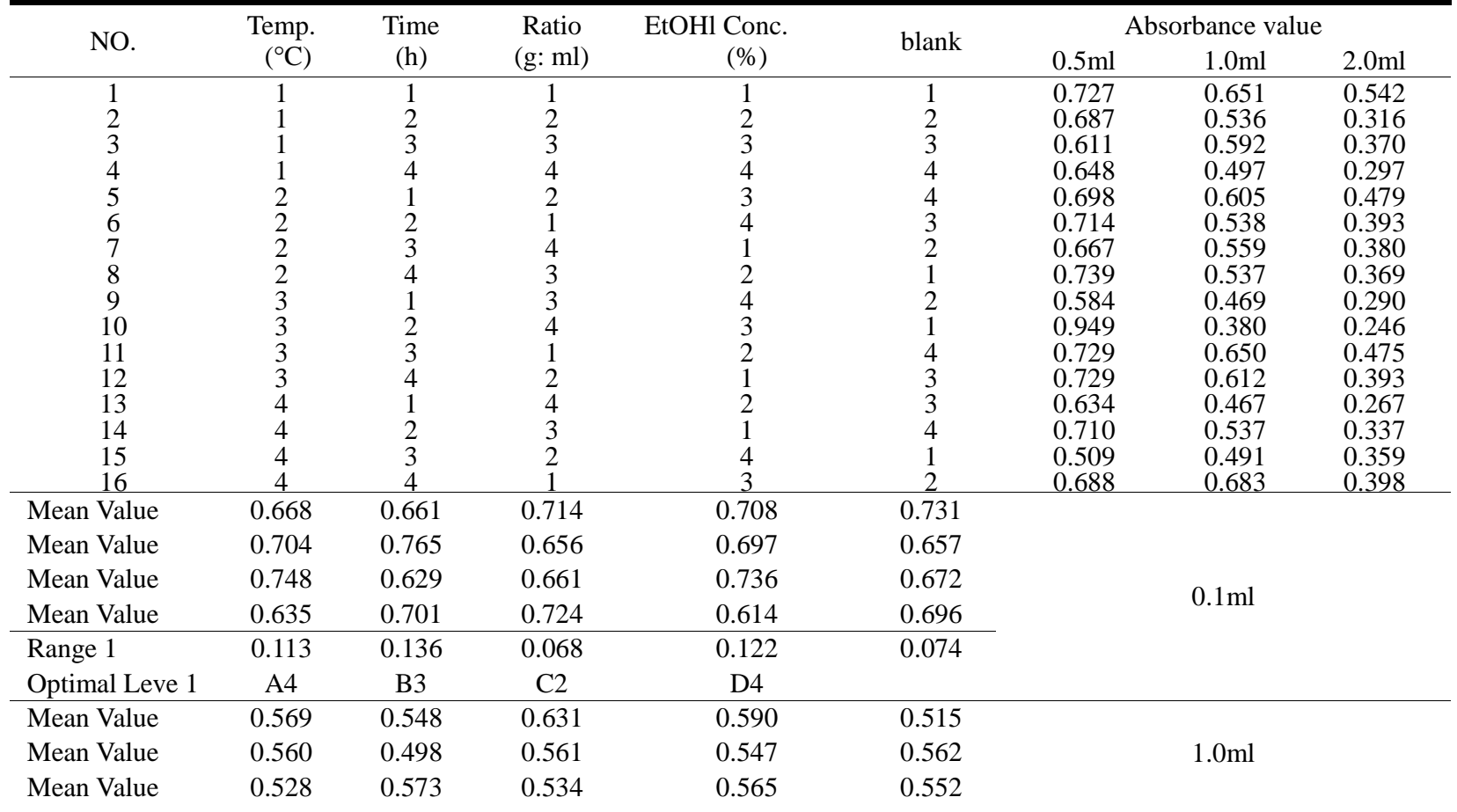




\begin{tabular}{lccccc} 
Mean Value & 0.544 & 0.582 & 0.476 & 0.499 & 0.572 \\
\hline Range 2 & 0.041 & 0.084 & 0.155 & 0.091 & 0.057 \\
OptimalLeve & $\mathrm{A} 3$ & $\mathrm{~B} 2$ & $\mathrm{C} 4$ & $\mathrm{D} 4$ & \\
\hline Mean Value & 0.381 & 0.394 & 0.452 & 0.413 & 0.379 \\
Mean Value & 0.405 & 0.323 & 0.387 & 0.357 & 0.346 \\
Mean Value & 0.351 & 0.396 & 0.341 & 0.373 & 0.356 \\
Mean Value & 0.340 & 0.364 & 0.297 & 0.335 & 0.397 \\
\hline Range 3 & 0.065 & 0.073 & 0.155 & 0.078 & 0.051 \\
Optimal Level & $\mathrm{A} 4$ & $\mathrm{~B} 2$ & $\mathrm{C} 4$ & $\mathrm{D} 4$ & $2.0 \mathrm{ml}$ \\
\hline
\end{tabular}

Result of determination content of extract alkaloids in chloroform phase in orthogonal experiment

Table $4 \mathrm{~L}_{16}\left(4^{5}\right)$ Project of orthogonal tests and the results of alkaloid determining in organic phase

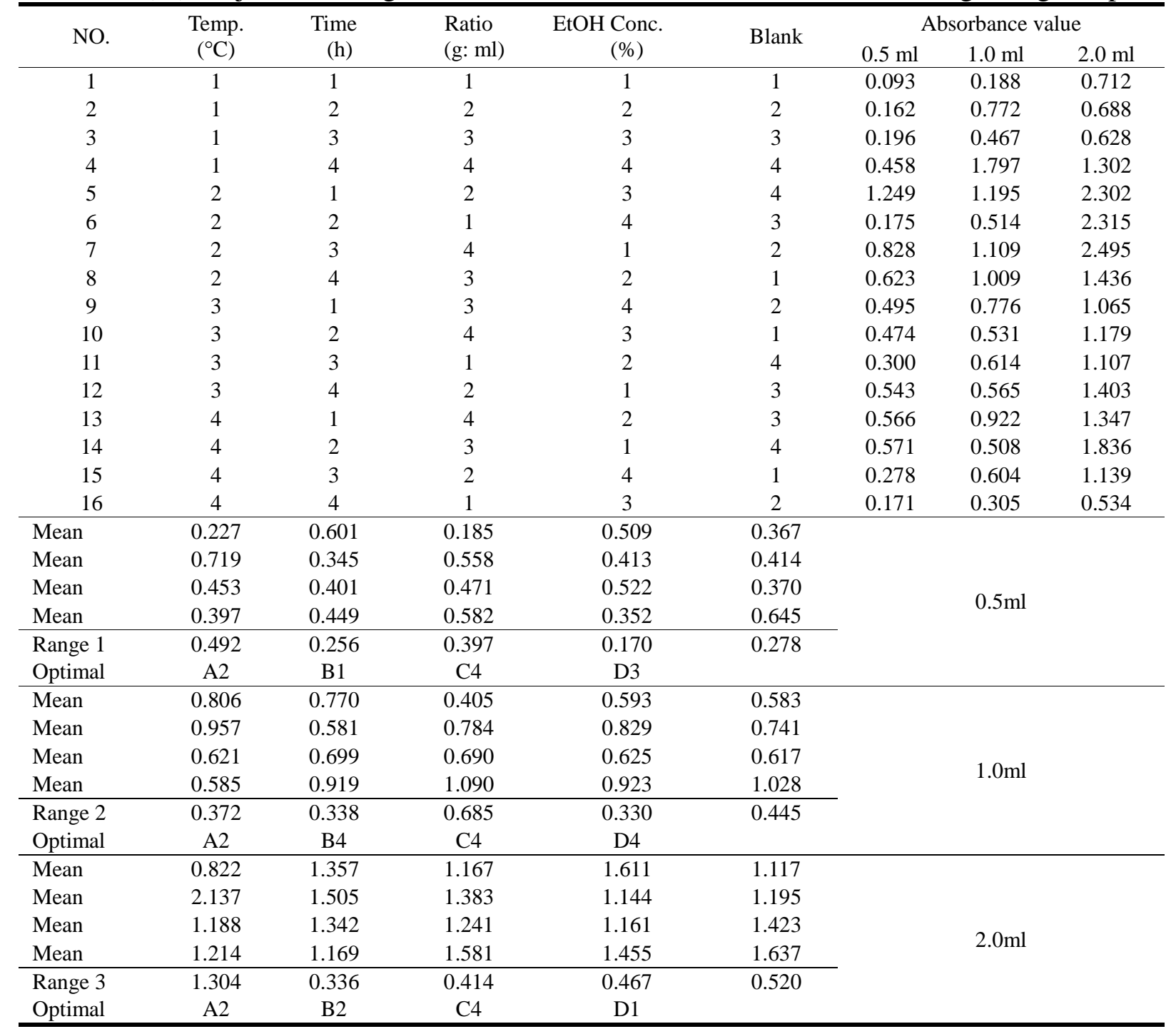

From table 4 it could be seen that the results of the 3 different sampling volume chloroform phase. According to the value of range (R), the efficacy of ZSS alkaloids have been influenced by four factors from high to low in order are extraction temperature $>$ solid to liquid ratio $>$ ethanol concentration > extraction time. In summary, the combination of optimal factors are $80 \%$ ethanol in solid : liquid equal $20: 1$ solution under $60^{\circ} \mathrm{C}$ for $4 \mathrm{~h}$.

In conclution, the highese extraction rate of optimum condition is $80 \%$ ethanol in solid : liquid equal 10:1 solution under $70{ }^{\circ} \mathrm{C}$ for $8 \mathrm{~h}$. From the optimal factors of determination content of extract alkaloids in aqua phase is $80 \%$ ethanol in solid : liquid equal $20: 1$ solution under $80{ }^{\circ} \mathrm{C}$ for 4 $\mathrm{h}$. From the optimal factors of determination content of extract alkaloids in chloroform phase is $80 \%$ ethanol in solid : liquid equal $20: 1$ solution under $60^{\circ} \mathrm{C}$ for $4 \mathrm{~h}$. Finally, regard the total 
alkaloids of extraction as the target, the best condition is $80 \%$ ethanol in solid : liquid equal 20:1 solution under $60^{\circ} \mathrm{C}$ for $4 \mathrm{~h}$.

Results of validate experiment

Table 5 The results of the reflux exrtraction of alkaloid in ZSS under optimized conditions

\begin{tabular}{|c|c|c|c|c|c|c|}
\hline \multirow[b]{2}{*}{ No } & \multicolumn{2}{|c|}{$0.5 \mathrm{mlSample}$ solution } & \multicolumn{2}{|c|}{ 1.0mlSample solution } & \multicolumn{2}{|c|}{ 2.0mlSample solution } \\
\hline & $\begin{array}{c}\text { Aqueous } \\
\text { phase }\end{array}$ & $\begin{array}{c}\text { Chloroform } \\
\text { phase }\end{array}$ & $\begin{array}{c}\text { Aqueous } \\
\text { phase }\end{array}$ & $\begin{array}{c}\text { Chloroform } \\
\text { phase }\end{array}$ & Aqueous phase & $\begin{array}{c}\text { Chloroform } \\
\text { phase }\end{array}$ \\
\hline $\begin{array}{l}\text { Verification } \\
\text { experiment }\end{array}$ & 0.918 & 1.345 & 0.699 & 1.885 & 0.613 & 2.579 \\
\hline
\end{tabular}

Followed the best condition from the orthogonal experiment (20\% acetic acid ethanol in solid : liquid equal 20:1 solution under $60{ }^{\circ} \mathrm{C}$ for $4 \mathrm{~h}$ ) as verification experiment, determination results of the extracts are shown in Table 5, which can be seen by the result that the extraction of the alkaloid content in the condition is higher than that of the orthogonal experiment. Therefore, the conditions above cloud be determined as the optimal extraction conditions.

\section{Conclusion}

The total alkaloids of ZSS was measured by spectrophotometric. Inadditionally, extraction solvent and acid solvent extraction, extraction time, extraction temperature, liquid to solid ratio and solvent concentration were optimized through the single factor experiment and orthogonal experiment. Finally getting the optimal reflux extraction conditions of total alkaloids of ZSS is: Using ethanol as solvent, with acetic acid as assistant extraction, 20\% acetic acid ethanol in solid : liquid equal 20:1 solution under $60^{\circ} \mathrm{C}$ for $4 \mathrm{~h}$ is the best extraction conditions

\section{Acknowledgements}

The authors would like to express their gratitude to the Importation and Development of High-Caliber Talents Project of Beijing Municipal Institutions (CIT\&TCD20154045), the Beijing Natural Science Fund (14L00184) and The Degree and Graduate Education Reform and Development Project of BUA in 2015 (2015YJS034) for the financial support of this study.

\section{References}

[1] Chinese Pharmacopoeia Commission. Pharmacopoeia of the people's Republic of China[M]. Beijing: chemical Industry Press, 2005: 254-255. (in Chinese)

[2] Q. Shi, Y. Zhou, P. Zhou, et al: J Pharm Prac Vol. 22 (2004), p. 94. (in Chinese)

[3] B.H. Han, M.H. Park, J.H. Park: Pure Appl. Chem. Vol. 61 (1989), p. 443.

[4] B.H. Han, M.H. Park: Arch. Pharmacal Res. Vol. 10 (1987), p. 203.

[5] J.W. Fu, W. Qiao, Z.H. Chen: J Tianjin Med Univ Vol. 11 (2005), p. 52. (in Chinese)

[6] L.H. Zhao, W. Qiao, L. Xu: Tianjin Pharm Vol. 19 (2007), p. 4. (in Chinese)

[7] T.L. Zhu, Z.S. Gao, L. Li, et al: Acta Acad Med Vol. 18 (2009), p. 420. (in Chinese)

[8] X.S. Yao. Natural medicinal chemistry[M]. People's Medical Publishing House, 1994, 459-468. (in Chinese)

[9] Y. Liu, Z.H. Yue, N. Zhang, et al: Chin Pharm Affa Vol. 23 (2009), p. 817. (in Chinese)

[10] H.G. Chen, Y.G. Yu, Q.X. Zeng: Food Machi Vol. 5 (2001), p. 16. (in Chinese)

[11] C. Zhang, H.B. Zhang, W.L. Huang: Chin Med Mat Vol. 28 (1997), p. 276. (in Chinese)

[12] P. Zhen, F.Z. Yang: Chin J Chin Mater Med Vol. 25 (2000), p. 504. (in Chinese)

[13] P. Chen, Z.R. Xing: Chin J Mod Appl Pharm Vol. 8 (1993), p. 15. (in Chinese)

[14] S.Z. Yin, H.K. Jin, B.Y. Jin, et al: Chin J Chin Mater Med Vol. 22 (1997), p. 296. (in Chinese)

[15] H.H. Byung, H.P. Myung, N.H. Yong: Phytochemistry Vol. 29 (1990), p. 3315.

[16] B.H. Han, M.H. Park, J.H. Park: Pure Appl. Chem. Vol. 61 (1989), p. 443. 
[17] B.H. Han, M.H. Park, Y.N. Han: Arch. Pharmacal Res. Vol. 12 (1989), p. 263.

[18] B.H. Han, M.H. Park: Arch. Pharmacal Res. Vol. 10 (1987), p. 203.

[19] B.H. Han, M.H. Park: Arch. Pharmacal Res. Vol. 12 (1989), p. 263.

[20] M. Tripathi, M.B. Pandey, R.N. Jha, et al: Fitoterapia Vol. 72 (2001), p. 507. 